\title{
COPD prevalence and its association with occupational exposures in a general population
}

\author{
A.M. Melville*,\#, T. Pless-Mullolï, O.A. Afolabi* and S.C. Stenton ${ }^{\#,+}$
}

ABSTRACT: The aim of this study was to ascertain the population prevalence of chronic obstructive pulmonary disease (COPD) in an area with past heavy industry and to establish the relative contributions of occupational and other risk factors.

We investigated respiratory symptoms and the prevalence of spirometrically-defined COPD in a population-based study in North-East England (UK) between 2002 and 2004. Questionnaires were posted to 6,000 males and 6,000 females, 45-69 yrs of age, who were randomly selected from a primary care database (response rate $64 \%, n=7,566$ ). Spirometric measurements were performed on 845 randomly selected responders. We defined COPD by the Global Initiative for Chronic Obstructive Lung Disease (GOLD) II criteria.

The prevalence of respiratory symptoms was $55 \%$. Symptoms were strongly associated with smoking, occupational exposures and hay fever. COPD was present in $10 \%$ of subjects. Its presence was significantly associated with occupational exposures, smoking and hay fever.

COPD is common in North-East England. Respiratory effects of occupational exposures can be detected within the general population: there were clear associations between occupational exposures and respiratory symptoms. The association with COPD was more marked in females.

KEYWORDS: Chronic obstructive pulmonary disease, epidemiology, occupational exposure, prevalence

hronic obstructive pulmonary disease (COPD) is a global health problem that causes substantial morbidity and mortality. It is increasing in prevalence and by 2020 it will be the third leading cause of death worldwide [1]. Despite its considerable social and economic importance, population-based epidemiological studies of its prevalence have lagged behind those of other common health problems. CHAPMAN et al. [2] recently noted that only 32 prevalence surveys of COPD had been reported up to 2001, compared with hundreds of studies of asthma and thousands relating to cancer and cardiovascular disease.

The lack of generally agreed diagnostic criteria has been an important limitation to the investigation of COPD. Symptoms relate poorly to lung function abnormalities limiting the value of questionnaires [3]. Variations in lung function diagnostic criteria can change prevalence estimates considerably [4] and the age distribution of the study population also has a marked effect
$[3,5]$. Studies from different centres often cannot be compared directly, limiting conclusions about geographic variation and temporal trends. However, recently introduced guidelines, such as those of the Global Initiative for Chronic Obstructive Lung Disease (GOLD), have helped standardise diagnostic practice and have facilitated national and international comparisons [6].

In addition to uncertainties about the true prevalence of COPD and its geographic variability, some aetiological issues also remain unresolved. Cigarette smoking is the principal risk factor. However, smoking explains no more than two-thirds of the variation in COPD prevalence in epidemiological studies, and often less [2, 3]. Occupational exposures to dusts, vapours and fumes have been established as risk factors by studies of coal miners and other working groups [7]. They are believed to be responsible for $\sim 15 \%$ of COPD overall but their influence is likely to vary geographically depending on their extent and nature, and may be

\section{AFFILIATIONS}

*Northumbria Healthcare Trust,

\# Institute of Health and Society,

Newcastle University, and

${ }^{+}$Royal Victoria Infirmary, Newcastle upon Tyne, UK

\section{CORRESPONDENCE}

A.M. Melville

Dept of Respiratory Medicine

Wansbeck General Hospital

Woodhorn Lane

Ashington

Northumberland

NE63 9JJ

UK

E-mail: alice.melville@nhct.nhs.uk

Received:

March 062009

Accepted after revision:

Dec 152009

First published online:

Jan 282010 
substantially higher in some areas [8]. Other COPD risk factors include atopy, social status, air pollution and genetic predisposition [1, 8-10].

Our study aimed to quantify the population prevalence of COPD in North-East England (UK), an area that until recently was characterised by heavy industry, such as mining and shipbuilding. Many middle-aged and elderly local residents were heavily exposed to dust, fumes and vapours during their working lives. This population therefore offered the opportunity to explore the relative contribution of occupational exposures to COPD in one of the most industrialised areas of Western Europe.

\section{MATERIALS AND METHODS}

\section{Study design}

This was a two-phased cross-sectional community survey of an urban population of $\sim 500,000$ residents. The main study objective was to ascertain the prevalence of spirometrically-defined COPD and explore its association with occupational exposures. Appropriate ethical approval was obtained from the Newcastle and North Tyneside Ethics Committee (Jarrow, UK).

\section{Sampling frame}

12,000 subjects (50\% male), 45-69 yrs of age were randomly selected from the local Primary Care Trust database, and were stratified equally into 5-yr age bands.

\section{Questionnaire design}

The self-completed questionnaire contained 21 questions ascertaining information on demographic and occupational details, respiratory symptoms and smoking. The questions were based on the European Compendium of Respiratory Standard Questionnaires for Adults [11]. Subjects were also asked to state if they had worked with any of the substances, or in any of the occupations illustrated in figure 1, and if so, for how long. UK census data from 2001 indicated that only $3.2 \%$ of the local population was non-white and no adjustment was made for ethnicity [12].

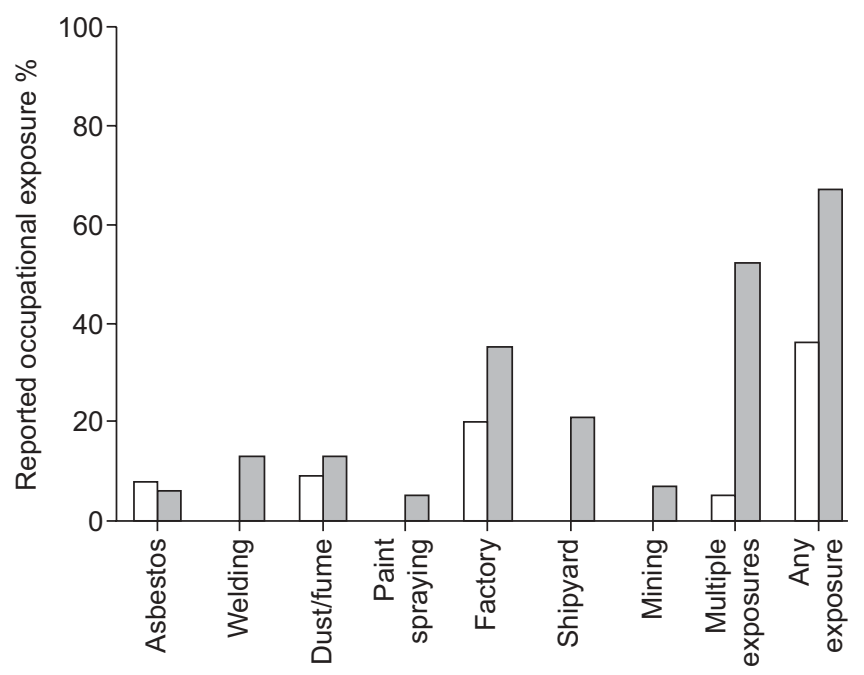

FIGURE 1. Specific occupational exposure in males ( $\square$ ) and females ( $\square$ ).

\section{Questionnaire administration}

Questionnaires were mailed between July and October 2002. Up to two reminders were sent to nonresponders. Data were coded by the Newcastle University Data Preparation Service (Newcastle upon Tyne, UK) and entered into a database.

\section{Lung function measurements}

Lung function measurements were carried out by the same trained personnel in two centres between September 2003 and August 2004. 1,516 subjects were invited to attend. 425 were selected at random from those mailed the questionnaire. The remainder were identified by stratifying questionnaire responders into five subgroups by the number of symptoms reported and selecting $24 \%$ from each subgroup. Participants were asked not to take inhaled short-acting bronchodilators for $4 \mathrm{~h}$ and long-acting bronchodilators for $24 \mathrm{~h}$ prior to testing. Height and weight were recorded. Forced expiratory volume in $1 \mathrm{~s}$ (FEV1) and forced vital capacity (FVC) were measured using PK Morgan rolling seal volume displacement spirometers (PK Morgan, Gillingham, UK), with software supplied by Collingwood Measurement (Packington, UK). The spirometers were calibrated daily in accordance with the manufacturer's instructions and all equipment complied with European Commission standards. Inter-laboratory assessments of consistency were undertaken by the supervising individuals measuring their own (stable) spirometry at the start of each session. FEV1 and FVC were re-measured $15 \mathrm{~min}$ after the inhalation of $200 \mu \mathrm{g}$ of salbutamol (GlaxoSmithKline, Uxbridge, UK) via a metered-dose inhaler and spacer device. All measurements were corrected to BTPS (body temperature, pressure-saturated) and compared with values derived from the European Community for Steel and Coal (ECSC) prediction equations [13]. The best of at least three technically satisfactory measurements was recorded.

\section{Definition of COPD}

COPD was defined as post-bronchodilator $\mathrm{FEV} 1<80 \%$ of the predicted value and an FEV1/FVC ratio <0.7) representing moderate or severe disease, i.e. stage II or above using GOLD criteria [6]. Alternative definitions including FEV1/FVC $<0.7$ (GOLD stage I), and FEV1 below the lower limit of normal (LLN) [13], were explored.

\section{Statistical analysis}

The study was designed to have $80 \%$ power to detect a $5 \%$ difference in symptom prevalence in any subgroup that comprised $\geqslant 15 \%$ of the study population at the $5 \%$ level of significance. SPSS (version 15.0; SPSS Inc., Chicago, IL, USA) and Stata (College Station, TX, USA) were used for statistical analysis. Subgroups were compared using Chi-squared and unpaired t-tests. Binary logistic regression for complex samples was used for categorical dependant variables to allow for the stratification of the population by age and sex. Multiple logistic regression for complex samples was used when the dependant variables were continuous.

\section{RESULTS}

7,566 valid and 138 invalid questionnaire responses were received, a response rate of $64 \%$. Characteristics of the questionnaire responders are detailed in table 1 . As reported previously from North-East England [14], the study population 
was largely static, with only $10 \%$ of individuals having lived the majority of their lives outside the region.

Older subjects and females were more likely to respond to the questionnaire: the median age of responders was 58 yrs versus 56 yrs for nonresponders $(p<0.001)$. Differences in the response patterns between those responding to the first and to subsequent mailings of the questionnaire suggested that those with symptoms $(p=0.001)$, lighter smokers $(p<0.001)$, those of higher social class $(p<0.001)$ and those without occupational exposures were more likely to respond $(p=0.01)$ [15]. There were differences between males and females in their exposure profiles (fig. 1).

Predictors of respiratory symptoms are shown in table 2. The effect of occupational exposures was generally more marked in females, indicated by the significant sex-exposure interaction term. There were associations with the specific occupational exposures to coal mining $(p<0.01)$, factory work $(p<0.05)$, work with solvents $(\mathrm{p}<0.05)$, welding and shipyard work $(\mathrm{p}<0.05)$. Analyses using the duration of exposure for each category did not strengthen any of these associations.

The characteristics of those attending for lung function testing are shown in table 3. 15\% reported an established diagnosis of asthma, 9\% chronic bronchitis and 2\% emphysema. $15 \%$ of males and $7 \%$ of females (10\% overall) fulfilled the diagnostic criteria for COPD (table 3). Logistic regression analysis showed associations with occupational exposures, smoking, and hay fever (table 4). Details regarding the prevalence and severity of COPD according to smoking history are illustrated in figure 3. There was a strong sex-exposure interaction with a greater influence of occupational exposure in females

\begin{tabular}{|c|c|c|c|}
\hline \multirow[t]{2}{*}{ TABLE 1} & \multicolumn{3}{|c|}{$\begin{array}{l}\text { Characteristics of questionnaire responders } \\
\text { according to sex }\end{array}$} \\
\hline & & Males & Females \\
\hline \multicolumn{4}{|c|}{ Demographic characteristics } \\
\hline Subjects & & 46 & 54 \\
\hline Age yrs & & $58(52-64)$ & $57(52-64)^{\star \star \star}$ \\
\hline Home owr & ship & 75 & $77^{\star \star \star}$ \\
\hline Lived loca & most of life & 89 & 91 \\
\hline Occupation & exposure & 67 & $36^{\star \star \star *}$ \\
\hline \multicolumn{4}{|c|}{ Smoking history } \\
\hline Never smc & & 30 & $44^{\star \star \star}$ \\
\hline Ex-smoker & & 45 & $32^{\star \star \star}$ \\
\hline Current sn & & 25 & 24 \\
\hline Pack-yrs fc & smokers & $26(13-44)$ & $22(9-36)^{\star * \star}$ \\
\hline \multicolumn{4}{|c|}{ Self-reported symptoms } \\
\hline Any respir & ry symptoms & 57 & $53^{\star \star \star}$ \\
\hline Cough & & 23 & $18^{\star \star \star}$ \\
\hline Sputum & & 30 & $20^{\star \star \star}$ \\
\hline Dyspnoea & & 33 & 34 \\
\hline Wheeze & & 42 & $38^{\star \star \star}$ \\
\hline History of & $y$ fever & 24 & $28^{\star \star \star}$ \\
\hline
\end{tabular}

compared with males. No significant smoking-exposure interaction was found.

Including all subjects with FEV1/FVC $<0.7$ (GOLD stage I) increased the apparent prevalence of COPD to $25 \%$ and generally weakened associations, although cigarette smoking (OR 1.3 per 10 pack-yrs (95\% CI 1.2-1.4)), sex (OR 1.5 for males (95\% CI 1.0-2.5)) and age (OR 1.8 per 10 yrs (95\% CI 1.3-2.5)) remained significant. Using pre-bronchodilator measurements increased the apparent prevalence of COPD to $14 \%$. Defining COPD as FEV1 $<$ LLN and FEV1/FVC $<$ LLN, identified fewer cases of COPD (50 versus 84 ) but the associations with occupational exposure (OR 2.99 (95\% CI 1.43-6.26)), smoking (OR 1.26 per 10 pack-yrs (95\% CI 1.11-1.42)) and hay fever (OR 2.58 (95\% CI 1.37-4.88)) were unchanged. Defining COPD as FEV $1<80 \%$ predicted and FEV1/FVC $<$ LLN identified even fewer cases of COPD (44 versus 84). Relations between occupational exposure (OR 3.53 (95\% CI 1.58-7.89), smoking (OR 1.21 per 10 pack-yrs (95\% CI 1.06-1.38)) and hay fever (OR 1.85 (95\% CI 0.94-3.63)) were again maintained but the association with hay fever was of borderline significance. The relationship between occupational exposure and COPD strengthened as the definition of COPD became tighter. Only seven subjects $(0.8 \%)$ had a restrictive abnormality (FEV1 and FVC below the LLN and FEV1/FVC $\geqslant 70 \%$ ).

\section{DISCUSSION}

We identified COPD in 10\% of our 45-69-yr-old population of North-East England, a rate that is within the wide range of COPD prevalences reported by previous studies. For example MATHESON et al. [16] identified COPD in 7\% of 45-70-yr-olds in Australia, whereas MurTAGH et al. [17] identified COPD in 14\% of 40-69-yr-olds in Northern Ireland (UK). The range of recent European COPD prevalence estimates varies at least two-fold, and worldwide estimates vary about 10-fold [2].

The lack of standardised study methodology is likely to contribute substantially to variations in reported COPD prevalence [18], though not all such variations can be explained in this way. PENA et al. [19] reported prevalences ranging 5-18\% in seven regions of Spain. Similar study methods were used in each region and little, if any of the variation was explained by differences in smoking rates. The 2005 Latin American Project for the Investigation of Obstructive Lung Disease (PLATINO) study reported prevalences ranging $8-20 \%$ in five Latin American cities [20]. Approximately half of those prevalences remained unexplained after adjustment for covariates. CABALLERO et al. [21] found prevalences of GOLD stage I COPD (FEV1/FVC <0.7) ranging 6-13\% in Colombia and the international Burden of Obstructive Lung Disease (BOLD) study identified prevalences in males ranging from $11 \%$ in China to $24 \%$ in South Africa [22]. Overall, the evidence suggests substantial geographical variation in COPD prevalence that remains largely unexplained.

Under some circumstances, occupational exposures are likely to contribute to variations in COPD prevalence. Dusts, fumes and vapours are recognised to cause COPD and are believed to contribute $\sim 15 \%$ to its overall prevalence [8]. Coal miners have been the most extensively studied occupational group, and a number of workplace studies have suggested that heavy exposures to coal mine dust and smoking are of similar 
TABLE 2 Significant predictors of respiratory symptoms ${ }^{\#}$

\begin{tabular}{|c|c|c|c|c|c|}
\hline Male sex & & $1.3(1.1-1.6)$ & $0.7(0.6-0.9)$ & & \\
\hline Smoking per 10 pack-yrs & $1.3(1.3-1.3)$ & $1.3(1.2-1.3)$ & $1.3(1.3-1.3)$ & $1.3(1.3-1.4)$ & $1.3(1.2-1.3)$ \\
\hline Hay fever & $1.8(1.6-2.1)$ & $1.9(1.7-2.2)$ & $1.8(1.6-2.0)$ & $2.9(2.6-3.3)$ & $2.5(2.2-2.8)$ \\
\hline Any occupational exposure & $2.0(1.6-2.1)$ & $2.2(1.8-2.8)$ & $1.9(1.5-2.3)$ & $1.8(1.5-2.2)$ & $2.1(1.7-2.5)$ \\
\hline
\end{tabular}

Data are presented as $\mathrm{OR}(95 \% \mathrm{Cl}) .{ }^{*}$ : potential explanatory variables considered in the final model: property ownership (the proxy for socio-economic status), current area of residence (Newcastle or North Tyneside), area lived majority of life, any occupational exposure, ever smoked (yes/no), pack-yrs smoked, hay fever/allergies causing nasal stuffiness (the proxy for atopy), weight, sex-occupational exposure interaction.

potency in causing COPD [23]. Effects of equal magnitude have been seen in studies of silica-exposed gold miners and a range of other workplace dusts and fumes has been shown to contribute to COPD [23]. Such effects are likely to be detectable in general population surveys if the subjects have experienced heavy occupational exposures.

Our study adds to a growing body of evidence that respiratory effects of occupational exposures can be detected not only within specific industrial sectors but also within the general

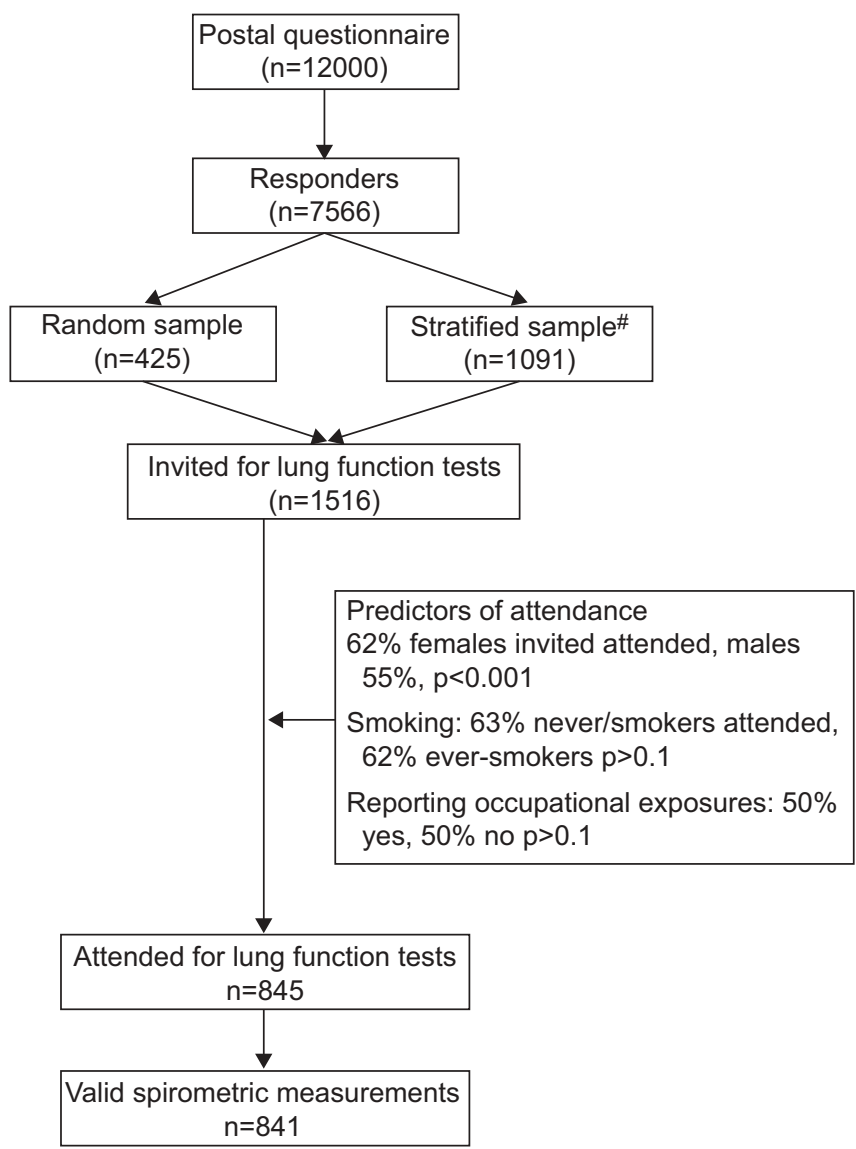

FIGURE 2. Study design. \#: see Materials and Methods for details. population. We identified clear associations between a range of occupational exposures and respiratory symptoms. Overall, those with a history of occupational exposures were twice as likely than unexposed subjects to report respiratory symptoms. There were significant associations with some specific occupational exposures, i.e. coal mining, welding, factory work, and solvent exposure. Two of these exposures (welding fume and coal mining) are established causes of COPD [7, 24], and factory work in North-East England is likely to have been associated with a range of exposures that are plausibly associated with COPD. Solvent exposures have previously been identified as being associated with COPD [25]. A wide range of associations with other specific exposures has been reported but no consistent pattern has yet emerged. The most relevant exposures are likely to vary depending on the nature of local industries. The notion that so many exposures have been linked to COPD is consistent with the view that the disease is a potential consequence of exposure to any airborne dust, fume or vapour.

There was a less clear association between occupational exposures and COPD as defined by lung function abnormalities.

\begin{tabular}{|c|c|c|}
\hline TABLE 3 & \multicolumn{2}{|c|}{$\begin{array}{l}\text { Characteristics of those attending for lung } \\
\text { function }\end{array}$} \\
\hline Subjects n & & 845 \\
\hline Males \% & & 49 \\
\hline Age yrs (IQR) & & $59(52-64)$ \\
\hline Occupational & exposure & 50 \\
\hline \multicolumn{3}{|c|}{ Mean FEV1 post-bronchodilator $L$} \\
\hline Males & & 3.19 \\
\hline Females & & 2.38 \\
\hline \multicolumn{3}{|c|}{$\%$ pred $(95 \% \mathrm{Cl})$} \\
\hline COPD & & 10 \\
\hline COPD ever $\mathbf{s}$ & noked & 77 \\
\hline Undiagnosed & COPD & 6 \\
\hline
\end{tabular}




\begin{tabular}{|c|c|c|c|}
\hline \multirow[t]{2}{*}{ TABLE 4} & \multicolumn{3}{|c|}{$\begin{array}{l}\text { Univariate and multivariate analysis of chronic } \\
\text { obstructive pulmonary disease (COPD) }{ }^{\#} \text { against } \\
\text { potential explanatory variables }\end{array}$} \\
\hline & & Univariate analysis & Multivariate analysis \\
\hline \multicolumn{2}{|l|}{ Sex } & $2.3(1.4-3.6)$ & $3.29(1.3-7.8)$ \\
\hline \multicolumn{2}{|c|}{ Age per 10 yrs } & $1.6(1.2-2.9)$ & \\
\hline \multicolumn{2}{|c|}{ Any occupational exposure } & $2.3(1.4-3.7)$ & $3.09(1.3-6.9)$ \\
\hline \multicolumn{2}{|c|}{ Sex-exposure interaction } & & $0.39(0.1-1.0)$ \\
\hline \multicolumn{2}{|c|}{ Hay fever } & $1.6(1.0-2.6)$ & $2.59(1.4-4.2)$ \\
\hline \multicolumn{2}{|c|}{ Smoking per 10 pack-yrs } & $1.3(1.2-1.5)$ & $1.39(1.2-1.4)$ \\
\hline \multicolumn{4}{|c|}{$\begin{array}{l}\text { Data are presented as } \mathrm{OR}(95 \% \mathrm{Cl}) .{ }^{*} \text { : defined as force expiratory volume in } 1 \mathrm{~s} \\
\text { (FEV } 1)<80 \% \text { predicted and } \mathrm{FEV} 1 / \text { forced vital capacity }<0.7 \text {, representing } \\
\text { moderate or severe disease. } \because \text { : indicating a greater effect of exposure in } \\
\text { females. Potential explanatory variables considered as in table } 2 \text {. }\end{array}$} \\
\hline
\end{tabular}

Overall, we found statistically significant effects to be more marked in females compared with males. It was not clear whether the sex difference was related to differences in exposure or to differences in susceptibility. There is an increasing body of evidence that females respond differently to environmental agents and are possibly more susceptible [26, 27]. There are previous reports of occupational COPD specifically affecting females [16]. MATHESON et al. [16] demonstrated a four- to six-fold increased risk of chronic obstructive bronchitis in females exposed to mineral dusts, biological dusts, gases and fumes but no significantly increased risk in males in an Australian study.

There are some inevitable limitations to investigations such as ours. The response rate of $64 \%$ is within the range reported in similar studies [28]. The primary care database we used is known to contain inaccuracies because of changes in address, migration and death. In 1996, DEVEREux et al. [29] suggested that $79 \%$ of nonresponders had not received a questionnaire when using the same database. We were unable to verify receipt of the questionnaire within this study, but if the rate of inaccuracy was similar to that in the study by DEVEREux et al. [29], the response rate could have been as high as $87 \%$. MURTAGH et al. [17] used a similar primary care database and reported that at least $7 \%$ of their patients did not receive a questionnaire because of incorrect addresses. There was some further loss of participation for those invited for the laboratory studies, with $56 \%$ attending. This was similar to that reported in the study by MATHESON et al. [16].

The recruitment process was complicated by an initial attempt to stratify the population according to symptoms. This was abandoned and subjects were selected randomly within each symptom subgroup and in proportion with the frequency of symptoms in the overall population. The overall effect was equivalent to an entirely random sample. Correcting for the age and sex distribution of the local population [12] reduced our COPD prevalence estimate slightly to $10 \%$.

There was some evidence of bias in recruitment, with females and older subjects over-represented. Such response patterns are frequently seen in epidemiological studies [30]. There was no evidence of bias in favour of those most likely to have been

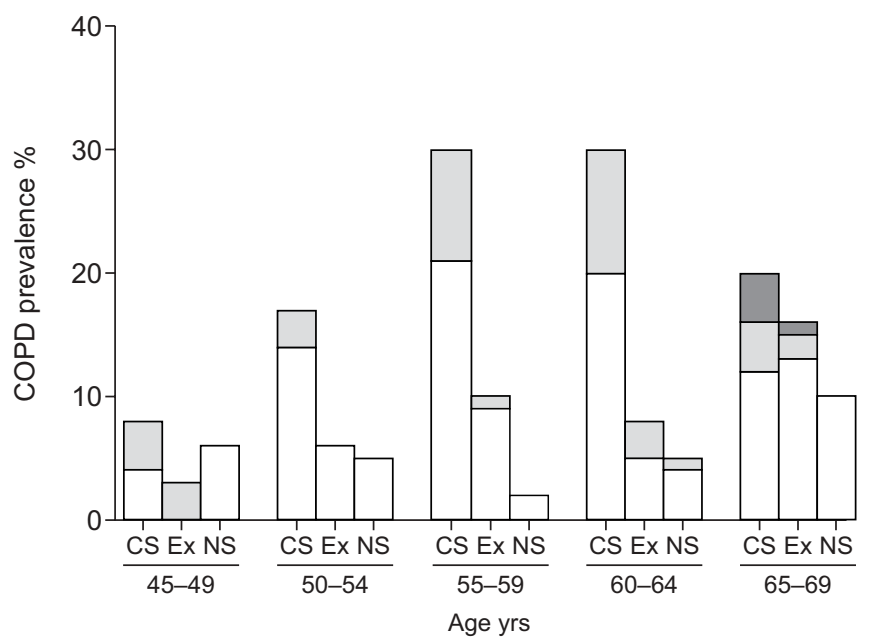

FIGURE 3. Prevalence of chronic obstructive pulmonary disease (COPD) by smoking history. CS: current smoker; Ex: ex-smoker; NS: nonsmoker. $\square$ : Global linitiative for Chronic Obstructive Lung Diseases (GOLD) stage 2; 1 : GOLD stage 3; : GOLD stage 4

particularly affected by workplace exposure. A letter mailed with the questionnaire advised potential subjects that occupational exposures were being investigated together with other environmental factors but this was not given undue prominence. The possibility of recall bias is of particular concern, with symptomatic subjects more likely to report occupational exposures leading to a spurious association with COPD. Our assessment of occupational exposures was relatively crude, but previous studies suggest that, in general population settings, associations can be demonstrated as readily with subjectreported exposures as with more complex assessments, such as job-exposure matrices [25].

We did not exclude those with asthma because of the potentially unreliable nature of the diagnosis, because asthma and COPD co-exist in many subjects, and since asthma and airway hyperresponsiveness may be important risk factors for COPD [2]. Atopy, which is closely associated with asthma, appeared to be an important risk factor for COPD.

The epidemiology of COPD is complex and changing. The current focus is rightly on increased smoking in developing countries and the increasing worldwide prevalence of COPD. Adult smoking is declining in many industrialised countries but other potential risk factors for COPD, such as asthma, atopy, diet, and atmospheric pollution, are increasing or changing, making it difficult to predict and the overall trends in prevalence of the disease. Occupational exposures currently contribute substantially to COPD in some areas and might continue to do so unless carefully controlled and regulated.

\section{STATEMENT OF INTEREST}

None declared.

\section{ACKNOWLEDGEMENTS}

The authors thank M. Mason for performing the lung function testing and his administrative support together with S. and V. Hendrick (all Department of Respiratory Medicine, Royal Victoria Infirmary, Newcastle upon Tyne, UK). Thanks are extended to S. Corbett 
(Northumbria Healthcare NHS Foundation Trust, Newcastle upon Tyne, UK) for advice regarding the study database, and those in respiratory out-patients at the Royal Victoria Infirmary (Newcastle upon Tyne, UK, and North Tyneside General Hospital, North Shields, UK).

\section{REFERENCES}

1 Murray CJ, Lopez AD. Alternative projections of mortality and disability by cause 1990-2020: Global Burden of Disease Study. Lancet 1997; 349: 1498-1504.

2 Chapman KR, Mannino DM, Soriano JB, et al. Epidemiology and costs of chronic obstructive pulmonary disease. Eur Respir J 2006; 27: 188-207.

3 Celli BR, Halbert RJ, Nordyke RJ, et al. Airway obstruction in never-smokers: results from the Third National Health and Nutrition Examination Survey. Am J Med 2005; 118: 1364-1372.

4 Shirtcliffe P, Weatherall M, Marsh S, et al. COPD prevalence in a random population survey: a matter of definition. Eur Respir $J$ 2007; 30: 232-239.

5 Bakke S, Baste V, Hanoa R, et al. Prevalence of obstructive lung disease in a general population: relation to occupational title and exposure to some airborne agents. Thorax 1991; 46: 863-870.

6 Pauwels RA, Buist AS, Ma P, et al. Global strategy for the diagnosis, management, and prevention of chronic obstructive pulmonary disease: National Heart, Lung, and Blood Institute and World Health Organization Global Initiative for Chronic Obstructive Lung Disease (GOLD): executive summary. Resp Care 2001; 46: 798-825.

7 Attfield MD. Longitudinal decline in FEV1 in United States coalminers. Thorax 1985; 40: 132-137.

8 Balmes J, Becklake M, Blanc P, et al. American Thoracic Society statement: Occupational contribution to the burden of airway disease. Am J Respir Crit Care Med 2003; 167: 787-797.

9 O'Connor GT, Sparrow D, Segal M, et al. Risk factors for ventilatory impairment among middle-aged and elderly men. The Normative Aging Study. Chest 1993; 103: 376-382.

10 Tashkin DP, Detels R, Simmons M, et al. The UCLA population studies of chronic obstructive respiratory disease: XI. Impact of air pollution and smoking on annual change in forced expiratory volume in one second. Am J Respir Crit Care Med 1994; 149: 1209-1217.

11 Pistelli F, Viegi G, Carrozzi L, et al. Appendix 3: Compendium of respiratory standard questionnaires for adults (CORSQ). Eur Respir Rev 2001; 11: 118-143.

12 Office of National Statistics. Neighbourhood Statistics. www. neighbourhood.statistics.gov.uk/ Date last accessed: 2001. Date last updated: May 20102001.

13 Quanjer P-H, Tammeling GJ, Cotes JE, et al. Lung volumes and forced ventilatory flows. Report Working Party Standardization of Lung Function Tests, European Community for Steel and Coal. Official Statement of the European Respiratory Society. Eur Respir J 1993; 6: Suppl. 16, 5-40.
14 Pless-Mulloli T, Phillimore $\mathrm{P}$, Moffatt $\mathrm{S}$, et al. Lung cancer, proximity to industry, and poverty in northeast England. Environ Health Perspect 1998; 106: 189-196.

15 Drane JW. Imputing nonresponses to mail-back questionnaires. Am J of Epidemiol 1991; 134: 908-912.

16 Matheson MC, Benke G, Raven J, et al. Biological dust exposure in the workplace is a risk factor for chronic obstructive pulmonary disease. Thorax 2005; 60: 645-651.

17 Murtagh E, Heaney L, Gingles J, et al. Prevalence of obstructive lung disease in a general population sample: the NICECOPD study. Eur J Epidemiol 2005; 20: 443-453.

18 Halbert RJ, Natoli JL, Gano A, et al. Global burden of COPD: systematic review and meta-analysis. Eur Respir J 2006; 28: 523-532.

19 Pena VSM, Miravitlles MM, Gabriel RM, et al. Geographic variations in prevalence and underdiagnosis of COPD: Results of the IBERPOC Multicentre Epidemiological Study. Chest 2000; 118: 981-989.

20 Menezes AM, Perez-Padilla R, Jardim JR, et al. PLATINO Team. Chronic obstructive pulmonary disease in five Latin American cities (the PLATINO study): a prevalence study. Lancet 2005; 366: 1875-1881.

21 Caballero A, Torres-Duque CA, Jaramillo C, et al. Prevalence of COPD in five Columbian cities situated at low, medium, and high altitude (PREPOCOL Study). Chest 2008; 133: 343-349.

22 Buist AS, McBurnie MA, Vollmer WM, et al. International variation in the prevalence of COPD (The BOLD Study): a population-based prevalence study. Lancet 2007; 370: 741-749.

23 Stenton SC, Hendrick DJ. Airflow obstruction and mining. Occup Med 1993; 8: 155-170.

24 Chinn DJ, Stevenson IC, Cotes JE. Longitudinal respiratory survey of shipyard workers: effects of trade and atopic status. $\mathrm{Br}$ J Ind Med 1990; 47: 83-90.

25 Post WK, Heederik D, Kromhout $\mathrm{H}$, et al. Occupational exposures estimated by a population specific job exposure matrix and 25 year incidence rate of chronic nonspecific lung disease (CNSLD): the Zutphen Study. Eur Respir J 1994; 7: 1048-1055.

26 Dransfield MT, Washko GR, Foreman MG, et al. Gender differences in the severity of CT emphysema in COPD. Chest 2007; 132: 464-470.

27 Han MH, Postma D, Mannino DM, et al. Gender and chronic obstructive pulmonary disease. Why it Matters. Am J Respir Crit Care Med 2007; 176: 1179-1184.

28 Brogger J, Bakke P, Eide GE, et al. Contribution of follow-up of nonresponders to prevalence and risk estimates: a Norwegian respiratory health survey. Am J Epidemiol 2003; 157: 558-566.

29 Devereux G, Ayatollahi T, Ward R, et al. Asthma, airways responsiveness and air pollution in two contrasting districts of northern England. Thorax 1996; 51: 169-174.

30 de Marco R, Verlato G, Zanolin E, et al. Nonresponse bias in EC Respiratory Health survey. Eur Respir J 1994; 7: 2139-2145. 